\title{
Case mix, costs, and outcomes - differences between faculty and community services in a university hospital
}

\section{Citation}

Garber, Alan M., Victor R. Fuchs, and James F. Silverman. 1984. Case mix, costs, and outcomes - differences between faculty and community services in a university hospital. New England Journal of Medicine 310, 19:1231-1237.

\section{Published Version}

10.1056/NEJM198405103101906

\section{Permanent link}

http://nrs.harvard.edu/urn-3:HUL.InstRepos:11642548

\section{Terms of Use}

This article was downloaded from Harvard University's DASH repository, and is made available under the terms and conditions applicable to Other Posted Material, as set forth at http:// nrs.harvard.edu/urn-3:HUL.InstRepos:dash.current.terms-of-use\#LAA

\section{Share Your Story}

The Harvard community has made this article openly available.

Please share how this access benefits you. Submit a story.

\section{Accessibility}




\title{
SPECIAL ARTICLE
}

\section{CASE MIX, COSTS, AND OUTCOMES}

\section{Differences between Faculty and Community Services in a University Hospital}

\author{
Alan M. Garber, M.D., Ph.D., Victor R. Fughe, Ph.D., ani James F. Silverman, M.D.
}

\begin{abstract}
To gain insight into the possible consequences of prospective payment for university hospitals, we studied 2025 admissions to the faculty and community services of a university hospital, measuring differences in case mix, costs, and mortality in the hospital. The faculty service had more of the patients with costly diagnoses, but even after adjustment for diagnosis-related groups (DRGs), costs were 11 per cent higher on the faculty service (95 per cent confidence limits, 4 to 18 per cent). The percentage differential was greatest for diagnostic costs. The differential was particularly large -70 per cent $(95$ per cent confidence limits, 33 to 107 per cent) - for patients with a predicted probability of death of 0.25 or greater.
\end{abstract}

$\mathrm{P}$ ROSPECTIVE payment is a cornerstone of federal and state plans to control health-care costs. ${ }^{1}$ It is also perceived as a threat to the financial viability of academic medical centers, whose costs per admission exceed those of community hospitals. ${ }^{2,3}$ Many investigators attribute higher costs to the distinctive mix of patients cared for in teaching hospitals." Thesc patients undergo extensive diagnostic investigation, reccive more aggressive treatment, and stay in the hospital longer - in part because they often present with more complex problems than their counterparts in nonteaching hospitals. Each hospital's case mix changes little from year to year. ${ }^{5}$ If academic medical centers continue to serve patients like those they have admitted in the past and to provide them with the same level of care, their revenues will depend on the case-mix adjustment applied to prospective payment.

The case-mix measure that will be applied under Medicare - the use of diagnosis-related groups (DRGs) - is already in use in Maryland and New Jersey. ${ }^{6}$ DRGs are groupings of diagnostic categories drawn from the International Classification of Diseases (ninth edition, Clinical Modification) and modified by the inclusion of major surgical procedures, patient age, and the presence of important complications or concurrent illnesses. ${ }^{7}$ Currently there are 467 DRGs, chosen to minimize the variance in costs within each group. "Teaching hospitals anticipating DRG-based payment schedules will find little reassurance in previous studies of the relation between hospital costs and case mix. These studies have shown that teaching hos-

From the Stanford University Medical Center and the National Bureau of Economic Research. Address reprint requests to Dr. Fuchs at the Nationa! Bureau of Economic Research, 204 Junipero Serra Blvd., Stanford, CA 943051298.

Supported by a grant from The Robert Wood Johnson Foundation to the National Bureau of Economic Research.

Any opinions expressed are those of the authors and not those of the National Bureau of Economic Research.
The in-hospital mortality rate was significantly lower on the faculty service after adjustment for case mix and patient characteristics $(P<0.05)$; the difference was particularly large for patients in the high-death-risk category. Comparision of a matched sample of 51 pairs of admissions from the high-death-risk category confirmed the above results with respect to costs and in-hospital mortality, but follow-up revealed that the survival rates were equal for the two services at nine months after discharge.

The effect of prospective payment on the cost of care will be closely watched; we conclude that it will also be important to monitor the effect on outcomes, including hospital mortality rates. (N Engl J Med 1984; 310:1231-7.)

pitals have higher costs even when case mix is held constant. $3,9,10$ There has been little discussion of the contribution, if any, of higher costs to better patient outcomes. Both policy makers and the hospitals need to know the causes of these cost differences and their implications.

We explored these issues by comparing patients who were admitted to the faculty and community services of a major university-afliliated hospital, measuring the contribution of case mix and other patient characteristics to differences in costs between the two services. We identified subsets of patients with particularly large cost differences and explored the possible causes of those differences. Finally, we investigated whether higher expenditures were associated with differences in outcomes and explored the implications for hospital costs and performance under prospective payment. By studying differences within a single hospital, we implicitly held constant wage rates, costs of materials and supplies, laboratory fees, pharmacy prices, quantity and quality of nursing, and similar factors that confound comparisons between different hospitals.

\section{Methods}

\section{Sample and Data Base}

The basic population consisted of all the admissions of patients 45 veats of atge and over at the Stanford Iniversity Hospital during 1981. The sample wats limited to admissions of patients whose illne'sse's placed them in D)R(is meeting these criteria: (1) the DRG; hat to hate accounted for at least 20 admissions to each of the faculty and community services; and (2) there had to have been 10 or more deaths in the 1)R(; in 1981. The second criterion ensured adequate variation in survival for the purposes of analysis of outcoume.

leull-(ime faculty members served as attending physicians for the patients admitted to the faculty service. All other patients were adonitted to either the community teathing or the community nonteaching service. Referring community physicians schected cases having particulat educational value for the teaching service; these 
included some of the sickest community-service patients with some of the most complicated diseases. House staff and students cared for these patients under the supervision of community physicians. Their freedom to order tests or diagnostic procedures for these patients was more limited than on the faculty service. The nonteaching service consisted of the two thirds of community-service patients who received no routine house-staff care. 'The 43 admissions that lacked a specification of physician type were excluded, to leave a final sample of 1007 faculty-service and $1018 \mathrm{community}$-service admissions in 12 DRGs. These DRGs accounted for 16.2 per cent of all admissions and 29.5 per cent of all costs of patients 4.5 years of age and over.

The data were generated from a data base known as the "Ciare Monitoring System." 'This system uses discharge data from medical records, including information about patient demographics, physician activity, outcomes, diagnoses, and procedures. The data are classified by DRG, and the medical-record data are merged with the financial record, which assigns charges according to service unit. For this study, the service units were aggregated to form threc categories: routine (including room and central service), diagnostic, and therapeutic services. The allocation of charges was made by one of us, who is the hospital chief of staff (J.F.S.), by review of the cost centers (e.g., radiology) and service units (e.g., chest x-ray films). Thus, respiratory-therapy charges were assigned to the therapeuticservice category, clinical laboratory studies to the diagnostic category, radiology-chest $x$-ray films to the diagnostic category, and radiology-angioplasty to the therapeutic category. Costs here refer to patient charges rather than to the actual value of resources used. Because the ratio of resource costs to charges varies according to type of charge, differences in charges may either overestimate or underestimate cost differences if the distribution of charges according to type varies greatly between the faculty and community services. 'To determine whether this was a serious problem, separate cost/charge ratios were calculated for the routine, diagnostic, and therapeutic categories, and these ratios were applied separately to the faculty and community services in accordance with the distribution of charges in each service. When this result was compared with the actual charge data used, the difference was less than one percentage point for the average DRG and less than one tenth of one percentage point for the comparison of 51 matched pairs discussed below. 'Thus, charges are used throughout as an index of costs.

\section{Predicting Hospital Outcome (Survival)}

The method of maximum likelihood was used to estimate a multiple logistic equation relating the probability of death during hospitalization to a number of personal characteristics. The dependent variable took the value of one if admission terminated in death, and the value of zero otherwise. Independent variables were age and dummy variables (each observation takes a value of one or zero) for sex, urgency of admission, race, area of residence, previous discharge, and each of the 12 DRGs. A predicted probability of death was computed for each patient by applying the estimated logistic equation to the values of the variables for the patient.

\section{Cost and Survival Adjustment}

We determined the contribution of patient mix to observed differences in costs and survival by adjusting for 1)RG; alone and for DRGs with personal characteristics. These adjustments are analogous to indirect age adjustments. 'To adjust costs for DRGs and other characteristics, we first derived a measure of predicted costs. In the first stage, linear regressions were estimated with the natural logarithm of costs as the dependent variable and the following as exogenous variables: dummy variables for sex, religion, type of insurance, urgency of admission, race, location of residence, previous discharge, age category, and DRG. To adjust for DRG alone we performed similar regression analyses omitting the other variables. The regression coefficients were then applied to obtain the predicted cost for each admission. 'The geometric means of the ratio of actual to predicted costs (i.e., adjusted-cost ratios) were computed for the faculty-service and the community-service patients separately. Finally, the adjusted cost was calculated as the adjusted cost ratio for faculty-service (or community-service) patients multiplied by the mean costs for both groups combined. The formula for adjusted costs for the faculty service was

$$
\text { Adj. costs }=\exp \left[\sum_{i=1}^{N_{f}} \frac{\log C_{i}-\log \hat{C}_{i}}{N_{i}}\right](\bar{C}),
$$

where $C_{i}$ are the actual costs for the $i$ th faculty-service patient, $\hat{C}_{i}$ are that patient's predicted costs, $\bar{C}$ is the mean cost for faculty- and community-service patients combined, and $\mathrm{N}_{\mathrm{r}}$ is the total number of faculty-service patients in the group.

Outcomes were adjusted in an analogous manner. 'To obtain the predicted risk of death for an individual patient, adjusting for personal characteristics as well as DRGs, we used the value of the predicted probability of death for that patient. 'The adjusted-risk ratio for any group of patients was defined as the proportion of the group who actually died divided by the mean predicted probability of death for the group. The adjusted risk was simply the adjustedrisk ratio for either a community or faculty group multiplied by the percentage of the combined population who died. Statistical significance was determined by testing for differences in means for costs and differences in proportions for mortality, using a two-tailed test.

\section{Matched Observations in Patients with a High Death Risk}

All patients whose predicted probability of death was equal to or greater than 0.25 were identified for chart review and follow-up. This included 60 faculty-service and 140 community-service patients. Pairs consisting of one patient from each service were then matched by age, sex, and DRG. Close matches were found for 55 pairs of patients, but 4 pairs were excluded because medical records could not be located for one member of the pair. The remaining 51 pairs were compared for costs and outcomes, their medical charts were reviewed, and their survival status during the year after discharge was ascertained.

\section{Results}

Patients admitted to the faculty and community services differed in several important respects, as shown in Table 1. The former were much more likely to be admitted for cardiac surgery or treatment of lymphoma or leukemia. A disproportionate number of patients on the community service had diagnoses of cerebrovascular disorders, chronic obstructive pulmonary disease, or heart failure and shock. The faculty-service patients were substantially younger (seven years, on average), less likely to have been admitted on an emergency basis, and much less likely to live within a half hour's drive of the hospital. The distributions (not shown in the table) of patients according to race, religion, and insurance coverage were similar in the two services, except that those on the community side included a larger percentage of Medicare patients, reflecting the difference in age distribution.

\section{Costs}

Table 2 shows that costs were higher on the faculty service in nine of the DRGs. The overall cost differential of 59.6 per cent was substantially reduced to 10.8 per cent (95 per cent confidence limits, 3.7 to 18 per cent) when costs were adjusted for differences in the distribution of cases across the 12 DRGs. Additional adjustment for the socioeconomic characteristics of the patients had virtually no effect on the overall cost 
differential of over $\$ 1,200$ per case. Similarly, the exclusion of 16 outliers (costs in excess of $\$ 100,000$ ) had very little effect on the differential. Adjusted average length of stay did not differ significantly between the two services; adjusted cost per day was significantly higher on the faculty service.

Patients were assigned to four risk categories on the basis of their predicted probability of death. These categories corresponded to values of 0.25 or higher (9.9 per cent of the admissions), between 0.15 and 0.24 (22.9 per cent), between 0.05 and 0.14 (27.6 per cent), and less than 0.05 (39.6 per cent). Table 3 shows that the cost differential was small and statistically insignificant for patients with low predicted probability of death. It was largest among the most seriously ill patients - those who, at the time of admission, had an estimated probability of death of 0.25 or greater. Among such patients, those treated by faculty had costs that were 70 per cent higher $(95$ per cent confidence limits, 33 to 107 per cent) than those treated by community physicians, after adjustment for case mix as measured by DRGs. When costs were disaggregated into threc major categories, the adjusted percentage differential was greatest for diagnostic costs and smallest for routine costs.

\section{Mortality}

Faculty-service patients incurred higher costs, but Tables 2 and 4 show that they also had better outcomes as measured by deaths per 100 admissions. Inhospital mortality rates were higher for patients on the community service in 11 of the 12 DRGs. Even after adjustment for DRGs and socioeconomic characteristics, the community-service patients were 34 per cent (95 per cent confidence limits, 1 to 66 per cent) more likely to be dead at discharge. Disaggregation according to predicted probability of death shows that the survival difference was most pronounced for the highrisk patients, the same ones who had the largest differential in costs.

Analysis of the relation between the cost and mortality differentials reveals substantial differences across the 12 DRGs. In one set of DRGs $(089,105$, 107,274 , and 403) there was a large mortality differential and virtually no difference in cost. In a second set $(082,172$, and 203), there were large differentials in both costs and mortality. And in a third set $(014,087$, 088 , and 127), there was a large cost differential, but adjusted mortality rates were similar on the two services. Interestingly, the distribution of patients according to service and DRG appears to be responsive to these cost-mortality trade-offs. In the first set of DRGs, in which the faculty service had substantially lower mortality with no increase in cost, this service accounted for 63 per cent of the admissions. By contrast, in the third set of DRGs, in which the faculty service had substantially higher costs without lower mortality, only 27 per cent of the patients were treated by faculty physicians. In the intermediate set of
DRGs, admissions were more equally divided, with 44 per cent cared for on the faculty service.

\section{Matched Pairs}

The results of a comparison of matched observations shown in Table 5 strongly support the conclusions drawn from the larger sample and offer additional insights concerning the differences between the two services. The 51 admissions to the faculty service were matched by DRG, age, and sex with 51 admissions to the community service. The patients came from the following DRGs (numbers of pairs shown in parentheses): 014 (5), 082 (16), 087 (5), 172 (4), 203 (14), and 274 (7). All patients had a death risk of 0.25 or higher. Within this matched group the average cost was more than twice as high in the faculty service. Moreover,

Table 1. Percentage Distribution of Admissions According to Diagnosis-Related Group (DRG), Patient Characteristics, and Type of Physician.

\begin{tabular}{|c|c|c|}
\hline Characteristics & $\begin{array}{l}\text { Faculity } \\
\text { Physicians }\end{array}$ & $\begin{array}{l}\text { Community } \\
\text { Physicians }\end{array}$ \\
\hline \multirow[t]{2}{*}{ Number of admissions } & 1007 & 1018 \\
\hline & \multicolumn{2}{|c|}{ percent } \\
\hline \multicolumn{3}{|l|}{ DRG } \\
\hline $0 / 4$ Cerebrovascular disorders & 4.6 & 15.3 \\
\hline O82 Respiratory neoplasms & 6.1 & 6.9 \\
\hline 087 Pulmonary edema and respiratory failure & 2.0 & 2.3 \\
\hline 088 Chronic obstructive pulmonary disease & 5.0 & 10.8 \\
\hline 089 Simple pneumonia & 2.6 & 6.2 \\
\hline 10.5 Cardiac-valve procedure & 19.2 & 5.7 \\
\hline 107 Coronary bypass & 37.2 & 23.2 \\
\hline 127 Hear failure and shock & 4.9 & 14.8 \\
\hline 172 Digestive-tract cancer & 2.5 & 4.0 \\
\hline 203 Pancreatic or hepatobiliary cancer & 2.4 & 2.8 \\
\hline 274 Malignant breast disorders & 2.7 & 2.9 \\
\hline 403 Lymphoma or leukemia & 11.0 & 5.0 \\
\hline \multicolumn{3}{|l|}{ Emergency status } \\
\hline Elective & 5.1 & 3.6 \\
\hline Urgent & 54.9 & 28.2 \\
\hline Emergent & 40.0 & 68.2 \\
\hline \multicolumn{3}{|l|}{ Discharge within past six months } \\
\hline Yes & 18.6 & 22.5 \\
\hline No & 81.4 & 77.5 \\
\hline \multicolumn{3}{|l|}{ Residence distance * } \\
\hline$<30$ minutes & 12.4 & 55.3 \\
\hline $31-60$ minutes & 20.2 & 14.5 \\
\hline $61-120$ minutes & 27.7 & 18.6 \\
\hline$\geqslant 121$ minutes & 38.0 & 6.7 \\
\hline Unknown & 1.7 & 4.9 \\
\hline \multicolumn{3}{|l|}{ Sex } \\
\hline Female & 34.9 & 46.6 \\
\hline Male & 65.1 & 53.4 \\
\hline \multicolumn{3}{|l|}{ Age } \\
\hline $45-64$ & 57.6 & 34.7 \\
\hline $65-74$ & 31.5 & 31.2 \\
\hline$\geqslant 75$ & 10.9 & 34.1 \\
\hline
\end{tabular}

*Approximate travel time to hoxpital. 
Table 2. Cost per Admission and Hospital Mortality According to Type of Physician.*

\begin{tabular}{|c|c|c|c|c|}
\hline \multirow[t]{2}{*}{ Diagnosis-Reiati:d Group (DRG) } & \multicolumn{2}{|c|}{ Cost plir Admission } & \multicolumn{2}{|c|}{$\begin{array}{c}\text { Hospital Deaths per } \\
100 \text { admissions }\end{array}$} \\
\hline & FACULTY & COMMUNITY & PACULTY & COMMUNITY \\
\hline & \multicolumn{2}{|c|}{ dollars } & & \\
\hline 014 Cercbrovascular disorders & $9,097 \dagger$ & $4,865 \dagger$ & 19.6 & 21.8 \\
\hline 082 Respiratory neoplasms & 5,274 & 4,439 & 14.8 & 28.6 \\
\hline $\begin{array}{l}087 \text { Pulmonary edema and } \\
\text { respiratory failure }\end{array}$ & $13,688 \ddagger$ & $4,903 \ddagger$ & 30.0 & 17.4 \\
\hline $\begin{array}{l}088 \text { Chronic obstructive } \\
\text { pulmonary disease }\end{array}$ & 8,872 & 7,539 & 6.0 & 7.3 \\
\hline 089 Simple pneumonia & 7,630 & 8,379 & 7.7 & 14.3 \\
\hline 105 Cardiac-valve procedure & 25,054 & 22,924 & 4.7 & 8.6 \\
\hline 107 Coronary bypass & 19,159 & 18,075 & 2.1 & 3.0 \\
\hline 127 Heart failure and shock & 5,163 & 4,364 & 12.2 & 14.6 \\
\hline 172 Digestive-tract cancer & 7,684 & 4.713 & 8.0 & 26.8 \\
\hline $\begin{array}{l}203 \text { Pancreatic or hepato- } \\
\text { biliary cancer }\end{array}$ & 5,846 & 4,217 & $16.7 \ddagger$ & $48.3 \ddagger$ \\
\hline 274 Malignant breast disorders & 4,063 & 4,259 & 11.1 & 26.7 \\
\hline 403 Lymphoma or leukemia & 9,452 & 10,341 & 10.8 & 19.6 \\
\hline All 12 DRGs & $15,313 \S$ & $9,592 \S$ & $7.2 \S$ & $14.9 \$$ \\
\hline All adjusted for DRG mix & $13,096 \dagger$ & $11,815 \dagger$ & $8.6 \dagger$ & $13.0+$ \\
\hline $\begin{array}{l}\text { All adjusted for DRG mix } \\
\text { and other characteristics }\end{array}$ & $13,071+$ & $11,840 \dagger$ & $9.2 \ddagger$ & $12.3 \ddagger$ \\
\hline
\end{tabular}

this difference was not attributable to a few large outliers. In 41 of the 51 pairs, the patient on the faculty service had the higher costs. Much of the difference in cost per admission was associated with longer stays on the faculty service; however, cost per day was also significantly higher on that service. The difference in outcomes, as measured by status at discharge, was also substantial: the death rate was almost twice as high among patients on the community service.

Although these patients had been carefully matched according to several criteria, review of their medical charts revealed a large difference in the proportion who had a "DNR" ("Do not resuscitate") notation on their charts. Only 6 of the 51 patients admitted to the faculty service had a DNR notation, as compared with 26 on the community service. This could reflect objective differences in the medical condition of the patients that were not accounted for by DRG, age, sex, and predicted probability of death, or it could reflect subjective differences in patient or physician attitudes. Also, the low use of the DNR code on the faculty service may result from administrative difficulties faced by house officers who must obtain approval from the faculty supervisor in order to put this nota- tion on the chart. The difference in code status is large, but it does not explain the differences in costs and outcomes. For 23 pairs in which the faculty and community patients had the same code status (in 21 the code was "resuscitate"), the faculty-community differentials were similar to those for all the pairs. Among the 23 pairs, 19 of the faculty-service patients had higher costs.

A much higher percentage of the community-service patients were local residents (who could drive to the hospital in less than 30 minutes). We were able to match 22 pairs according to residence zone (19 were in the "local" zone), but this matching did not reduce the cost differential. Among the 22 pairs, 18 of the faculty-service patients had higher costs. The differential in mortality was smaller than for all the pairs, but the faculty-service patients still had lower death rates.

There is no doubt that a higher percentage of the patients on the faculty service were discharged alive, but there is considerable interest in knowing how much longer they lived. The last line of Table 5 and Figure 1 provide answers to that question. For 48 pairs it was possible to ascertain whether the patient lived for at least one year after discharge or, if not, what the date of death was. The percentage surviving for one year was quite low, and it was equal for the two services. Figure 1 shows that there was still a considerable difference in survival rates six months after discharge, but by the end of nine months the difference between the two services had disappeared.

\section{Discussion}

Our study, like studies comparing community and teaching hospitals, ${ }^{9,10}$ found that adjustment for case mix eliminated much of the cost differential between faculty and community service in this hospital. Never-

Table 3. Adjusted Costs According to Type of Cost, Predicted Probability of Death, and Type of Physician.*

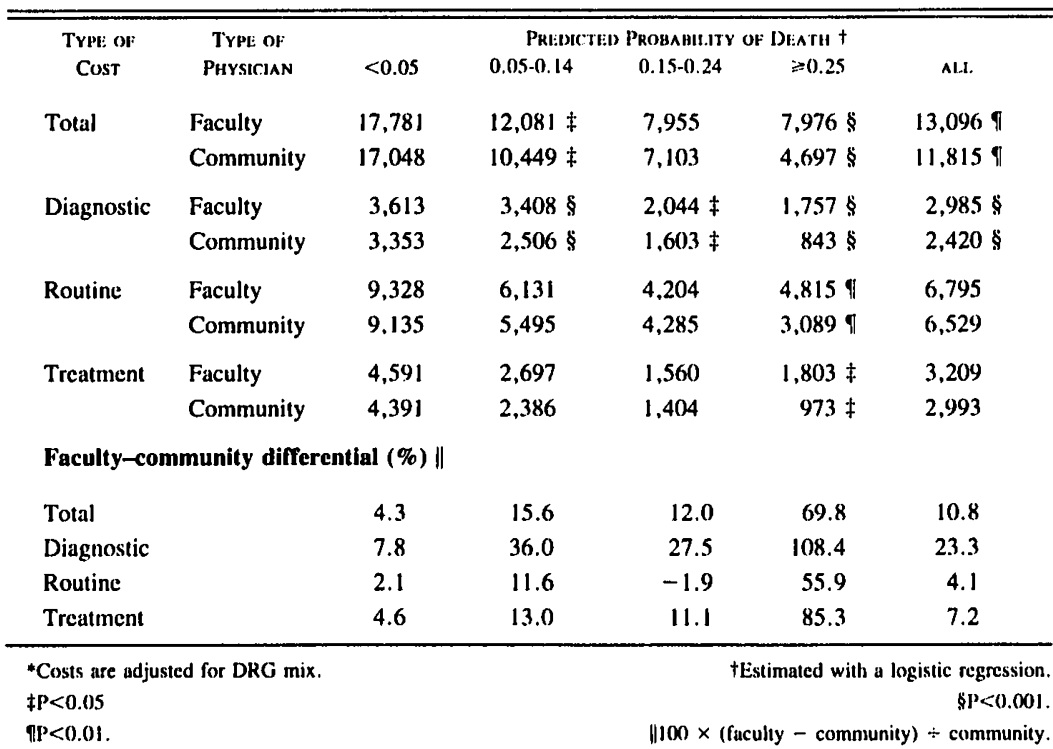


Table 4. Deaths per 100 Admissions According to Predicted Probability of Death and Type of Physician.

\begin{tabular}{|c|c|c|c|c|c|c|}
\hline & \multirow{2}{*}{$\begin{array}{l}\text { TYPE: OF } \\
\text { PHYSICIAN }\end{array}$} & \multicolumn{5}{|c|}{ Predicted Probahility of Death * } \\
\hline & & $<0.05$ & $0.05 \cdot 0.14$ & $0.15-0.24$ & $\geq 0.25$ & Al.t. \\
\hline \multirow[t]{2}{*}{ Unadjusted } & Faculty & 2.0 & 8.8 & 16.1 & 23.3 & $7.2+$ \\
\hline & Community & 3.8 & 9.7 & 21.4 & 34.3 & $14.9+$ \\
\hline \multirow{2}{*}{$\begin{array}{l}\text { Adjusted for DRG } \\
\text { \& other charac- } \\
\text { teristics } \ddagger\end{array}$} & Faculty & 2.1 & 8.8 & 16.2 & 22.8 & $9.2 \$$ \\
\hline & Community & 4.5 & 9.6 & 20.9 & 34.6 & $12.3 \$$ \\
\hline \multicolumn{7}{|c|}{$\begin{array}{l}\text { "Estimnted with a logistic regression. } \\
+\mathrm{P}<0.001 \text {. }\end{array}$} \\
\hline
\end{tabular}

theless, admissions to the faculty service generated higher costs within DRGs that could not be explained by other observed patient characteristics. These higher costs were accompanied by lower hospital mortality. Both cost and mortality differences were greatest for the high-risk group of patients.

A number of plausible explanations could be offered for these findings, with distinct and sometimes contradictory implications for health-care financing and for the costs of medical education. These may be divided into explanations based on differences in physician attributes and practice patterns, and those based on differences in patient populations.

\section{Physician Differences}

The differential in adjusted costs probably reflects in part the greater impact on the faculty service of the hospital's role as a training institution and referral center. House staff and medical students have major responsibilities for the care of patients on the faculty service. 'They have no role with respect to two thirds of the patients on the community service, and when they care for community-service patients, house officers have less autonomy than on the faculty service. These trainces, who learn by doing procedures and interpreting diagnostic tests, may order such studies more readily because of their putative educational value. The greater use of diagnostic services by trainees may also reflect their unwillingness or inability to rely as heavily as the more seasoned private physicians on the clinical examination."

Physician attitudes toward death may also have contributed to the more aggressive care on the faculty service. An unwillingness to allow patients to die may have driven some house officers to press for more care, even when it led to little or no improvement in patient out$+\mathrm{p}<0.05$. come. Private physicians, who knew their patients better, may have been more aware of the patients' own wishes concerning continued life support. In many cases, the patients' preferences may not have been known to the faculty physicians, who would have treated aggressively when in doubt. Finally, the inexperience of house oflicers and medical students may have led them to provide some services that had few benefits for the patient.

\section{Patient Differences}

Despite efforts to control for diagnosis and other patient characteristics, there may have been systematic differences between the patients on the two services in their medical condition, extent of workup before admission, or attitudes toward death. Chart review suggested that among the scriously ill patients, those admitted to the community service were more frequently admitted for purely supportive care and were less likely to receive extensive diagnostic workups or to be admitted to the intensive-care unit. Since the severity or stage of illness can vary considerably within the high-risk DRGs, control for DRG does not eliminate this source of variation in service intensity. A single DRG can include both a patient presenting with a metastasis and an unknown primary tumor, who receives an extensive diagnostic workup, and a moribund patient admitted for terminal care. Moreover, physicians on the community service typically cared for patients whom they had followed for long periods before hospitalization; thus, they may have been better able to avoid duplication of tests performed outside the hospital and to minimize other costs associated with the workup of new patients.

Table 5. Results of Analysis of 51 Matched Pairs.

\begin{tabular}{|c|c|c|c|c|}
\hline Characteristic & $\begin{array}{l}\text { Pacelity } \\
\text { Puysician }\end{array}$ & $\begin{array}{l}\text { Comaninity } \\
\text { PHysician }\end{array}$ & $\begin{array}{l}\text { Parvity } \\
\text { Mints } \\
\text { Commuinity * }\end{array}$ & $\begin{array}{l}\text { 95\% CON- } \\
\text { FImENCE: } \\
\text { LIMIT * }\end{array}$ \\
\hline Average age $(y r)$ & 68.7 & 69.7 & & \\
\hline $\begin{array}{l}\text { Average predicted proba- } \\
\text { bility of death }(\%)\end{array}$ & 31.9 & 32.8 & & \\
\hline Cost per admission $(\$)$ & $8.809 \dagger$ & $3,1.32+$ & 5677 & \pm 4.318 \\
\hline Length of stay (days) & $12.2 \dagger$ & $5.9 \dagger$ & 6.3 & $\pm \$ .0$ \\
\hline Cost per day $(\$)$ & $797 \dagger$ & $578+$ & 219 & \pm 193 \\
\hline Death in hospital $(\%)$ & $27.5 \dagger$ & $49.0+$ & -21.5 & \pm 19.2 \\
\hline "Do not resuscitate" code & $11.8 \ddagger$ & $51.0 \div$ & -39.2 & \pm 18.4 \\
\hline Local residence & $41.2 \ddagger$ & $76.5 \ddagger$ & -35.3 & \pm 19.5 \\
\hline \multicolumn{5}{|c|}{ Matched by code status (23 pairs) } \\
\hline Cost per admission (\$) & $10,7.56$ & 3.722 & & \\
\hline Probability of death $(\%)$ & 30.2 & 30.4 & & \\
\hline Death in hospital $(\%)$ & 17.4 & 34.8 & & \\
\hline \multicolumn{5}{|c|}{ Matched by residence ( 22 pairs) } \\
\hline Cost per admission (\$) & 11.476 & 3,570 & & \\
\hline Probability of death $(\%)$ & 29.9 & 29.8 & & \\
\hline Death in hospital (\%) & 31.8 & 40.9 & & \\
\hline $\begin{array}{l}\text { Survival for at least } \\
\text { one year (48 pairs) (\%) }\end{array}$ & 16.7 & 16.7 & & \\
\hline
\end{tabular}

*Difference and confidence limits are shown when difference is statistically significant $(P<0.05)$. 


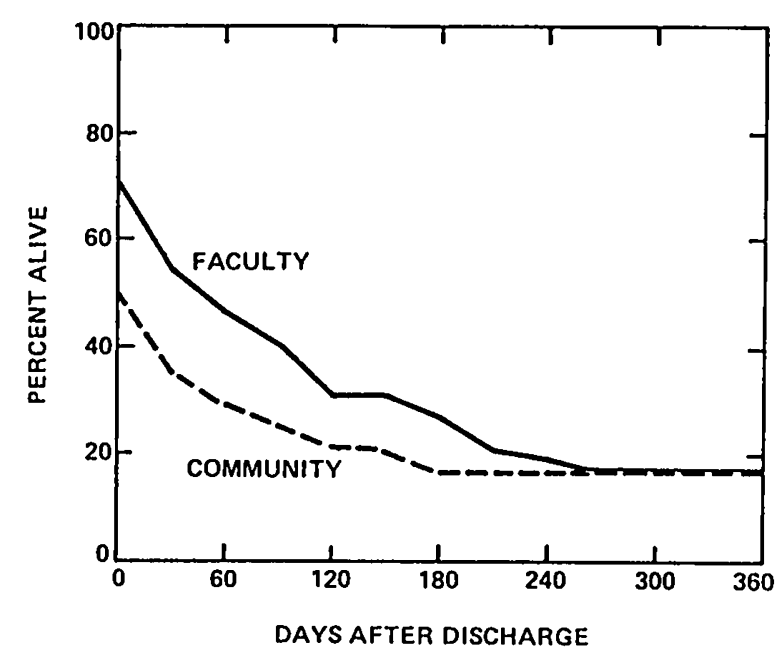

Figure 1. One-Year Survival Curves for 48 Matched Pairs of Patients, One of Each Pair Admitted to the Hospital's Faculty Service and the Other to Its Community Service.

Patient attitudes can also contribute to variation in the type and quantity of services provided. Patients having the same morbidity and the same prognosis will not seck the same care if their attitudes toward death and toward medical intervention differ. $A$ patient who is emotionally prepared to dic may not consent to intubation, mechanical ventilation, and cardiac resuscitation, though his equally ill fellow patient may desire such measures. The much higher proportion of "DNR" orders on the community service probably reflects such patient preferences, in addition to possible differences in prognosis and physician attitudes.

Many studies of hospital costs have assumed that hospital output could be represented by the volume of services provided. ${ }^{2}$ Such an approach has been justly criticized because inappropriate and inefective care add to such "output." Patients seek improvements in personal welfare from a hospital, not the tests and treatments themselves; improvement in patient welfare, however, is difficult to measure. Hospital survival is undoubtedly an important component of welfare, and according to this criterion, patients on the faculty service did better. In the matched sample of patients for whom follow-up data were available, the facultyservicc patients also had longer out-of-hospital survival. The distribution among I)RGs and the variation in other patient characteristics could only partially explain their lower mortality rates. Like the cost differentials, the outcomes deviated most for the group of patients with the highest risk and were likely to reflect differences in practice patterns as well as in the types of patients seen on each service.

'The more extensive use of diagnostic procedures and the more intensive care provided on the faculty service may have reduced mortality while generating higher costs. Because the patient populations may have differed, these results do not prove that faculty physicians reduced mortality by providing more care. But, if patients on the faculty service were less likely $(0)$ die simply because they were better risks, why did the faculty service attract them? It is unlikely that chance alone could cause so marked a disparity in patient populations. One possible explanation is that community physicians waited longer to admit their patients to the hospital than did their faculty counterparts. By substituting outpatient for inpationt services, they may have increased the proportion of their patients who were in the final stages of illness, while reducing hospital costs. Just as an all-inclusive measure of costs of illness, including outpatient services, might have shown less discrepancy between the faculty and community services, better control for stage of illness might have reduced the mortality differential.

Patient perceptions of the difference in practice styles may underlie systematic differences in the patient populations of the faculty and community services. Patients who desired or were likely to benedit from more care may have sought, or may have been referred to, members of the faculty. Not only did differences in underlying disease contribute to the mortality differences, but they appeared to determine what kind of care was appropriate. Notably, in the DRGs that included mainly faculty-service patients, those patients had lower mortality than communityservice patients, with similar costs. In the DRGs with mostly community-service patients, those patients had lower costs than faculty-service patients, with similar mortality. It is as if most of the patients were assigned to the service that would provide the best balance of costs and benefits. Neither the faculty nor the community medical practice was necessarily better or worse, merely different. There is no reason to expect or to desire patients with diverse conditions and attitudes to receive the same care or to have the same outcomes.

We have studied only onc hospital, and therefore our results may not be generalizable. On the other hand, the differences we observed between the faculty and community services in the same hospital are likely to understate the differences between separate teaching and community hospitals. In the hospital we studied, the same advanced, specialized facilities were available to the faculty-service and community-service patients, and house staff participated in the care of some community-service patients. Furthermore, faculty and community physicians in this hospital undoubtedly interacted more closely than faculty and community physicians in separate hospitals, contributing to a more homogeneous style of medicine. On the other hand, mortality differences in the 12 DRGs we studied were greater than in other DRGs, which had lower death rates.

It is difficult to ascertain whether the aggressive care on the faculty service contributed to the lower inhospital mortality; it is even more difficult to judge whether the reduced mortality was justified by the cost. In the matched sample of seriously ill patients, more than hall were discharged alive, but less than one fifth survived for as long as one year. 'The absence of relevant data on the postdischarge experience pre- 
cludes our drawing strong inferences from the survival curves shown in ligure 1 . We did not investigate the quality of life for the survivors, nor did we ascertain their source of postdischarge care or its cost. Many of the faculty-service patients presumably returned to their home communities after discharge and were cared for by their community physicians.

Even if the extra costs on the faculty service are attributable to the education of house staff and students, without corresponding patient benefits. these activities may be worthwhile. In that case, the question is not whether such care should continue, but whether it should be financed with patient-care revenues. If, on the other hand, these services have few educational benefits and little value to the patient, other methods of training physicians should be investigated. But if more intensive care helps some patients while educating house staff, effort should be devoted to identifying the patients most likely to benefit from such care. These are the patients who are likely to suffer most from prospective payment.

Under a prospective-payment plan, hospitals will have incentives to manipulate discharge diagnoses to fit patients into DRGs with higher payment schedules, to perform surgical procedures that shift patients to other DRGs, to limit hospital stays, and to minimize daily expenditures. ${ }^{12}$ Institutions that continue to practice the high-cost medicine that is typical of the faculty service will incur financial penalties. less aggressive services will become more common. Institutions will face the difficult challenge of both limiting expenditures and continuing to provide costly care to patients for whom it is appropriate. If hospital services become more homogencous, we may see hospital mortality rise. Undoubtedly, policy makers will closely monitor the effects of prospective payment on expenditures; an important potential consequence of prospective payment will be overlooked if they do not also monitor hospital mortality rates.

We are indebted to Byron Wm. Brown. Jr., for advice on statistical methods, and to Judy Anderson and Leslie Perreault for research assistance.

\section{REFERENCES}

1. Iglehart JK. The new era of prospective payment for hospitals. N Engt J Med 1982; 307:1288-92.

2. Sloan FA. Feldman RD. Steinwald AB. Effects of teaching on hospital costs. J Health Econ 1983: 2:1-28.

3. Watts CA. Klastorin TD. The impact of case mix on hospital cost: a comparative analysis. Inquiry 1980; 17:357-67.

4. Ament RP. Kobrinski EJ. Wood WR. Case mix complexity differences between teaching and nonteaching hospitals. J Med Educ 1981; 56:894-9(3).

5. Lave JR. Lave L.B. The extent of role differentiation among hospitals. Health Serv Res 1971: 6:15-38.

6. Iglehart JK. Medicare begins prospective payment of hospitals. $\mathbf{N}$ Engl J Med 1983; 308:1428-32.

7. Hornbrook MC. Hospital case mix: its definition, measurement and use. II Review of alternative measures. Med Care Rev 1982: 39:73-123.

8. Thompson JD. Fetter RB, Mross CD. Case mix and resource use. Inquiry $1975 ; 12: 300-12$.

9. Becker ER. Stcinwald B. Determinants of hospital casemix complexity. Health Serv Res 1981: 16:439-58.

10. Thompson JD. Fetter RB, Shin Y. One strategy for controlling costs in university teaching hospitals. J Med Educ 1978: 53:167-75.

11. Martz EW, Ptakowski R. Educational costs to hospitalized patients. J Med Educ 1978: 53:38.3-6.

12. Simborg DW. DRG creep: a new hospital-acquired disease. N Engl J Med 1981:304:160)2-4.

\section{MEDICAL INTELLIGENCE}

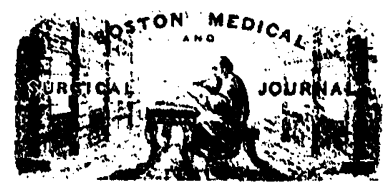

\section{CURRENT CONCEPTS}

\section{Recurrent Bacterial Infections in Children}

Richard B. Johnston, JR., M.D.

$\mathrm{T}$ HE presence of recurrent bacterial infections in a child raises the discomforting possibility of some type of underlying immunodeficiency disease. None of these diseases is common, and the money spent and blood withdrawn searching for them can be excessive. ' Yet the consequences of allowing such a disorder to go undiagnosed, even for days or weeks, can be

From the Department of Pediatrics, National Jewish Hospital and Research Center/National Asthma Center, and the University of Colorado School of Medicine, Denver. Address reprint requests to Dr. Johnston at National Jewish Hospital and Research Center, 3800 E. Colfax Ave., Denver, CO 80206. grave indeed. Thus, careful physicians must entertain the possibility of an immunodeficiency disease much more frequently than they expect to diagnose one.

How can this process of diagnostic exploration be accomplished efficiently? Beginning the process by selecting laboratory tests from the long complicated list that is available for this large group of uncommon disorders does not lend itself to efficiency, nor does it lead to realistic interpretation of test results. On the other hand, concentration on a few basic principles of host-microorganism interaction and on information about the patient's infections obtained from the history can permit logical selection of screening tests and give the physician more confidence in choosing the altemative of watchful waiting.

\section{Host-Microorganism Interactions: Patterns of Infection}

The mechanisms by which the human host defends itself against infection are summarized in the left column of 'Table 1 . On the other side of the battle line si: the microorganisms that are pathogenic for human beings, broadly grouped as extracellular, intracellular, and toxin producers. In any individual infection, a balance is struck between the opposing forces, and 